\title{
Endogenous carbon monoxide downregulates hepatic cystathionine- $\gamma$-lyase in rats with liver cirrhosis
}

\author{
SHI-BIN GUO ${ }^{1}$, ZHI-JUN DUAN $^{1}$, QIU-MING WANG ${ }^{1,2}$, QIN ZHOU $^{3}$, QING LI $^{4}$ and XIAO-YU SUN ${ }^{1}$ \\ ${ }^{1}$ Department of Gastroenterology, The First Affiliated Hospital, Dalian Medical University, Dalian, Liaoning 116011; \\ ${ }^{2}$ Department of Gastroenterology, Affiliated Beijing Chinese Medicine Hospital, Capital Medical University, Beijing 100000; \\ ${ }^{3}$ Department of Pharmacology, Dalian Medical University; ${ }^{4}$ Department of Gastroenterology, \\ Dalian Friendship Hospital, Dalian, Liaoning 116001, P.R. China
}

Received October 1, 2014; Accepted August 20, 2015

DOI: $10.3892 / \mathrm{etm} .2015 .2823$

\begin{abstract}
The aim of the present study was to investigate the effect of endogenous carbon monoxide (CO) on the hydrogen sulfide/cystathionine- $\gamma$-lyase $\left(\mathrm{H}_{2} \mathrm{~S} / \mathrm{CSE}\right)$ pathway in cirrhotic rat livers. The rats were allocated at random into four groups: Sham, cirrhosis, cobalt protoporphyrin (CoPP) and zinc protoporphyrin IX (ZnPP). The expression of hepatic CSE mRNA was evaluated using a quantitative polymerase chain reaction, while CSE protein expression was determined using immunohistochemical analysis. Hematoxylin and eosin staining was performed for the histological evaluation of liver fibrosis. The levels of $\mathrm{H}_{2} \mathrm{~S}$, alanine aminotransferase (ALT), aspartate aminotransferase (AST), total bilirubin (TBIL) and carboxyhemoglobin $(\mathrm{COHb})$ in the arterial blood were determined, in addition to the portal vein pressure. The mRNA and protein expression levels of hepatic CSE and the serum levels of $\mathrm{H}_{2} \mathrm{~S}$ were significantly decreased in the cirrhosis group compared with those in the sham group $(\mathrm{P}<0.05)$. Compared with the cirrhosis group, rats in the ZnPP group had significantly lower levels of serum ALT, AST and TBIL, arterial COHb and hepatic fibrosis, while hepatic CSE expression and the production of $\mathrm{H}_{2} \mathrm{~S}$ were significantly increased $(\mathrm{P}<0.05)$. The CoPP group exhibited decreased hepatic CSE expression and $\mathrm{H}_{2} \mathrm{~S}$ production, but aggravated hepatic function and fibrosis $(\mathrm{P}<0.05)$. In conclusion, the $\mathrm{H}_{2} \mathrm{~S} / \mathrm{CSE}$ pathway is involved in the formation of liver cirrhosis and serves a crucial function in protecting liver cells against the progression of liver fibrosis. Endogenous CO downregulates hepatic CSE mRNA and
\end{abstract}

Correspondence to: Professor Shi-Bin Guo or Professor Zhi-Jun Duan, Department of Gastroenterology, The First Affiliated Hospital, Dalian Medical University, 222 Zhongshan Road, Dalian, Liaoning 116011, P.R. China

E-mail: gsb@dl.cn

E-mail: cathydoctor@yahoo.com

Key words: hydrogen sulfide, cystathionine- $\gamma$-lyase, heme oxygenase-1, carbon monoxide, zinc protoporphyrin, cobalt protoporphyrin, biliary cirrhosis protein expression and the production of $\mathrm{H}_{2} \mathrm{~S}$ in rats with liver cirrhosis.

\section{Introduction}

Liver cirrhosis is the final stage of a chronic fibrotic process in the liver and is the primary cause of portal hypertension. Hyperdynamic circulation, which is secondary to the presence of systemic vasodilation, is an important factor in the aggravation and persistence of portal hypertension (1). Numerous mechanisms are involved in the development of systemic vasodilation, including increased synthesis of nitric oxide (NO) and carbon monoxide (CO) and the activation of $\mathrm{K}_{\text {ATP }}$ channels in the systemic and splanchnic arterial circulation (2). Previous studies have demonstrated that the hepatic heme oxygenase-1 (HO-1)/CO system (3) and NO/nitric oxide synthetase activity are overexpressed in rats with cirrhosis and contribute to portal hypertension (4)

In a previous study, hydrogen sulfide $\left(\mathrm{H}_{2} \mathrm{~S}\right)$ was identified as the third endogenous signaling gasotransmitter, in addition to $\mathrm{NO}$ and $\mathrm{CO}$, and was found to serve crucial functions in normal physiological conditions and in the process/progress of numerous diseases (5). $\mathrm{H}_{2} \mathrm{~S}$ is produced endogenously from cysteine by pyridoxal-5'-phosphate-dependent enzymes, including cystathionine- $\beta$-synthase and cystathionine- $\gamma$-lyase (CSE) (6), and is involved in vasorelaxation by activating the $\mathrm{K}_{\mathrm{ATP}}$ channel, a different mechanism from that of $\mathrm{NO}$ and $\mathrm{CO}(7,8)$.

NO is endogenously generated by vascular endothelial cells, while $\mathrm{H}_{2} \mathrm{~S}$ is derived from vascular smooth muscle cells and $\mathrm{CO}$ is endogenously produced by vascular endothelial and smooth muscle cells; therefore, it is plausible that these gaseous transmitters may interact in the regulation of biological functions (9-12). It has previously been shown that NO is able to upregulate the endogenous production of $\mathrm{H}_{2} \mathrm{~S}$ by increasing CSE gene expression (8). Additionally, $\mathrm{H}_{2} \mathrm{~S}$ is able to enhance vasodilation by $\mathrm{NO}$ at very low concentrations (8).

The effect of $\mathrm{CO}$ on the production of $\mathrm{H}_{2} \mathrm{~S}$ remains unclear. CSE is the primary enzyme involved in catalyzing the endogenous production of $\mathrm{H}_{2} \mathrm{~S}$ in mammalian hepatic tissue (13), and $>50 \%$ of the gas in the liver appears to be derived from CSE (13). The aim of the present study was to investigate the 
effect of endogenous $\mathrm{CO}$ on the $\mathrm{H}_{2} \mathrm{~S} / \mathrm{CSE}$ pathway in cirrhotic livers of rats by manipulating HO-1 enzyme activity via the intraperitoneal injection of zinc protoporphyrin IX (ZnPP), a specific HO-1 enzyme inhibitor, or cobalt protoporphyrin (CoPP), a specific HO-1 enzyme inducer.

\section{Materials and methods}

Animal care. The experimental protocols were approved by the Animal Care and Use Committee of Dalian Medical University (Dalian, China), in accordance with the guidelines established by the Canadian Council on Animal Care. A total of 45 healthy male Sprague Dawley rats (weight, 200-220 g; age, 6 weeks) were obtained from the Animal Center of Dalian Medical University (Dalian, China).

Reagents. TRIzol ${ }^{\circledR}$ reagent was obtained from Nanjing KeyGen Biotech, Co., Ltd. (KGA1203; Nanjing, China); a PrimeScript ${ }^{\circledR}$ RT Master Mix Perfect Real Time kit (DRR036A) and SYBR ${ }^{\circledR}$ Premix Ex Taq ${ }^{\mathrm{TM}}$ (DRR420A) were purchased from Takara Biotechnology Co., Ltd. (DRR036A; Dalian, China); polyclonal rabbit anti-mouse HO-1 and rabbit anti-mouse CSE antibodies were obtained from Wuhan Boster Biological Technology Co., Ltd. (Wuhan, China); anti-rabbit IgG was obtained from Fuzhou Maixin Biotechnology Development Co., Ltd. (MaxVision ${ }^{\mathrm{TM}}$ 2; Fuzhou, China); a Takara RNA polymerase chain reaction (PCR) kit (alfalfa mosaic virus) Ver. 3.0 was purchased from Takara Biotechnology Co., Ltd.; and CoPP and ZnPP were obtained from Sigma-Aldrich (St. Louis, MO, USA).

Animal model and grouping. Rats were randomly divided into four groups: Sham $(n=8)$, cirrhosis $(n=8), \operatorname{CoPP}(n=12)$ and $\mathrm{ZnPP}(\mathrm{n}=12)$. The rats were housed in a specific pathogen-free center, at a temperature of $24-26^{\circ} \mathrm{C}$ and at a relative humidity of $60-65 \%$. Rats were housed for 3 days prior to experimental protocols being initiated, were well fed and received water ad libitum. Bile duct ligation (BDL) was used to induce cirrhosis in rats in the cirrhosis, CoPP and $\mathrm{ZnPP}$ groups, according to the method described in a previous study (14). Laparotomy was performed under anesthesia with ether. The bile duct was isolated and double ligated with 3-0 silk. The abdominal wall and the skin were closed with 4-0 silk sutures, and antibiotic benzathine benzylpenicillin powder was sprinkled over the closed incision. The rats were continuously fed and housed for an additional 4-week period after surgery, and samples were collected. Rats in the sham group underwent laparotomy, with the bile duct isolated but not ligated. $\mathrm{ZnPP}$ and CoPP (Sigma-Aldrich) were dissolved in $0.2 \mathrm{~mol} / \mathrm{l}$ $\mathrm{NaOH}$, adjusted to $\mathrm{pH} 7.4$ and diluted in $0.85 \% \mathrm{NaCl}$. The final concentration was $1 \mathrm{mg} / \mathrm{ml}$, as previously described (15), and the resulting ZnPP and CoPP solutions were used to inhibit or induce HO-1 expression, respectively. Rats in the ZnPP and $\mathrm{CoPP}$ groups received an intraperitoneal injection of $\mathrm{ZnPP}$ or CoPP $(5 \mathrm{mg} / \mathrm{kg} /$ day $)$, respectively, for a week prior to sample collection. In addition, 5 of the initial 45 rats died prior to sample collection.

Sample collection. At 4 weeks after surgery, the rats were anesthetized with ether and the portal vein was isolated. A catheter, connected to pressure transducers (BL-420F data acquisition and analysis system; Chengdu Technology \& Market Co., Ltd., Chengdu, China), was placed in the portal vein to measure portal vein pressure (PVP). Arterial blood $(1 \mathrm{ml})$ was then collected using a heparinized syringe through the arterial catheter to measure carboxyhemoglobin $(\mathrm{COHb})$ levels using a RapidLab 1245 blood gas analyzer (Siemens Healthcare, Malvern, PA, USA) as an index for the CO level in arterial blood. Subsequently, $4 \mathrm{ml}$ portal venous blood was collected from the rats to measure serum levels of alanine aminotransferase (ALT), aspartate aminotransferase (AST) and total bilirubin (TBIL) using a Hitachi 7600-110 automatic biochemical analyzer (Hitachi, Ltd., Tokyo, Japan). One lobe of the liver was excised and tissue samples were fixed in $10 \%$ neutral formalin solution and embedded in paraffin; the remaining tissue was preserved at $-80^{\circ} \mathrm{C}$ for subsequent quantitative PCR (qPCR) analysis.

Measurement of serum $\mathrm{H}_{2} \mathrm{~S}$. Plasma samples $(75 \mu \mathrm{l})$ were mixed with $100 \mu 1$ distilled water and $300 \mu 1$ 10\% trichloroacetic acid. Then, $150 \mu 11 \%$ zinc acetate was added to Eppendorf

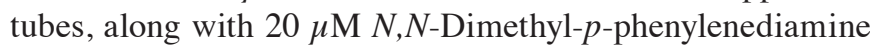
sulfate in $7.2 \mathrm{M} \mathrm{HCl}$ and $\mathrm{FeCl}_{3}(30 \mu \mathrm{M} ; 133 \mu \mathrm{l})$ in $1.2 \mathrm{M} \mathrm{HCl}$. After $15 \mathrm{~min}$ of incubation, the absorbance of the solution was measured at a wavelength of $670 \mathrm{~nm}$ using a UV-2550 spectrophotometer (Shimadzu Corp., Kyoto, Japan). All samples were assayed in duplicate, and the $\mathrm{H}_{2} \mathrm{~S}$ concentration was calculated against a calibration curve of NaHS $(0.122-250 \mu \mathrm{M})$.

Hepatic hydroxyproline (HYP) content. The HYP content in the liver was evaluated as an indirect index of tissue collagen content, according to a previously described method with modification (16), and was expressed in micrograms per gram of wet weight $(\mu \mathrm{g} / \mathrm{g})$.

Pathological analysis. Hematoxylin and eosin (H\&E) staining was performed according to standard procedures. The changes in liver cells, portal areas and central veins were assessed. In addition, Van Gieson's staining was conducted to visualize collagen type I. Sections were stained with Weigerts Resorcin Fuchsin at room temperature for $25 \mathrm{~min}$, washed with water, differentiated in acid alcohol, then washed in water for a further $10 \mathrm{~min}$. The sections were subsequently stained with Van Gieson for $5 \mathrm{~min}$, washed in water, dehydrated with ethanol, cleared using xylene and mounted for observation.

Immunohistochemical analysis. Liver tissues were fixed in a $10 \%$ neutral formalin solution, embedded in paraffin wax and cut into sections of $1 \times 0.8 \times 0.0004 \mathrm{~cm}$. Certain sections were stained with H\&E, while others underwent deparaffinization, rehydration and inactivation, prior to being incubated with rabbit-anti-mouse CSE and HO-1 polyclonal antibodies (1:50) at room temperature for $60 \mathrm{~min}$. Following incubation with the primary antibody, the sections were incubated with a secondary antibody (MaxVision 2) at room temperature for $15 \mathrm{~min}$. The sections were protected by coverslips following staining. The primary antibody was replaced by phosphate-buffered saline to serve as a negative control. Samples were incubated with $3 \% \mathrm{H}_{2} \mathrm{O}_{2}$ for $10 \mathrm{~min}$ at room temperature to eliminate endogenous peroxidase activity and to block nonspecific background 
Table I. Comparison of serum ALT, AST and TBIL among the groups.

\begin{tabular}{lccr}
\hline Group & ALT (U/l) & AST (U/l) & TBIL (mg/dl) \\
\hline Sham & $37.25 \pm 5.32$ & $172.61 \pm 7.32$ & $0.81 \pm 0.22$ \\
Cirrhosis & $96.43 \pm 8.02^{\mathrm{a}}$ & $287.58 \pm 10.49^{\mathrm{a}}$ & $11.85 \pm 1.87^{\mathrm{a}}$ \\
CoPP & $120.33 \pm 9.83^{\mathrm{b}}$ & $410.51 \pm 12.53^{\mathrm{b}}$ & $14.65 \pm 2.26^{\mathrm{b}}$ \\
ZnPP & $45.42 \pm 5.59^{\mathrm{b}}$ & $205.08 \pm 8.03^{\mathrm{b}}$ & $5.59 \pm 2.24^{\mathrm{b}}$
\end{tabular}

${ }^{\mathrm{a}} \mathrm{P}<0.05$ vs. sham group; ${ }^{\mathrm{b}}<0.05$ vs. cirrhosis group. ALT, alanine aminotransferase; AST, aspartate aminotransferase; TBIL, total bilirubin; CoPP, cobalt protoporphyrin; ZnPP, zinc protoporphyrin IX.

Table II. PVP and concentrations of endogenous $\mathrm{H}_{2} \mathrm{~S}$ and $\mathrm{COHb}$ among the groups.

\begin{tabular}{llrr}
\hline Group & $\mathrm{H}_{2} \mathrm{~S}(\mu \mathrm{mol} / \mathrm{l})$ & $\mathrm{COHb}(\%)$ & $\mathrm{PVP}\left(\mathrm{cmH}_{2} \mathrm{O}\right)$ \\
\hline Sham & $369.54 \pm 51.28$ & $0.23 \pm 0.05$ & $9.05 \pm 0.53$ \\
Cirrhosis & $142.85 \pm 38.58^{\mathrm{a}}$ & $0.50 \pm 0.20^{\mathrm{a}}$ & $14.87 \pm 2.02^{\mathrm{a}}$ \\
CoPP & $109.23 \pm 27.32^{\mathrm{b}}$ & $0.83 \pm 0.39^{\mathrm{b}}$ & $17.58 \pm 1.23^{\mathrm{b}}$ \\
ZnPP & $215.38 \pm 33.56^{\mathrm{b}}$ & $0.23 \pm 0.06^{\mathrm{b}}$ & $13.21 \pm 1.14^{\mathrm{b}}$ \\
\hline
\end{tabular}

${ }^{\mathrm{a}} \mathrm{P}<0.05$ vs. sham group; ${ }^{\mathrm{b}} \mathrm{P}<0.05$ vs. cirrhosis group. $\mathrm{COHb}$, carboxyhemoglobin; $\mathrm{PVP}$, portal vein pressure; CoPP, cobalt protoporphyrin; $\mathrm{ZnPP}$, zinc protoporphyrin IX.

staining. Subsequently, the sections were washed with distilled water, $0.01 \mathrm{M}$ citrate buffer $(\mathrm{pH}=6.0)$ was added and the sections were heated by microwave oven for $10 \mathrm{~min}$. Following cooling, the sections were washed with $0.1 \mathrm{M}$ PBS wash buffer 3 times. The immunoreactive signal was visualized by color deposition, using diaminobenzidine as a substrate. Yellow material in the cytoplasm was considered to indicate positive cells. Images were analyzed using Image-Pro Plus software, version 6.0 (Media Cybernetics, Inc., Rockville, MD, USA) to calculate the area and mean density of positive expression. Mean density was calculated as follows: Integrated optical density/area of interest. Results from five visual fields were averaged for each sample.

qPCR analysis. Quantification of the expression level of target genes was performed using qPCR. Total RNA was extracted from rat livers using TRIzol reagent (Nanjing KeyGen Biotech. Co., Ltd.). After extraction of RNA, reverse transcription was performed using random primers provided with the Takara PCR kit, following the manufacturer's instructions. The PCR amplification conditions were as follows: Pre-denaturation at $95^{\circ} \mathrm{C}$ for $30 \mathrm{sec}$, followed by 40 cycles of amplification by denaturing at $95^{\circ} \mathrm{C}$ for $5 \mathrm{sec}$, annealing at $60^{\circ} \mathrm{C}$ for $1 \mathrm{~min}$ and extending at $72^{\circ} \mathrm{C}$ for $30 \mathrm{sec}$. PCR cycling was performed using a Mx3005P qPCR system (Agilent Technologies, Inc., Santa Clara, CA, USA). The relative quantity of mRNA for each gene was normalized against the quantity of the housekeeping gene $\beta$-actin. Each sample was run and analyzed in triplicate. The primer sequences for CSE were as follows: 5'-GAGCCG GAGCAATGGAGTTC-3' (forward) and 5'-GGATTTCCA GAGCGGCTGTA-3' (reverse). The primer sequences for $\beta$-actin were: 5'-GGAGATTACTGCCCTGGCTCCTA-3' (forward) and 5'-GACTCATCGTACTCCTGCTTGCTG-3' (reverse). The primers were designed and synthesized by Takara Biotechnology Co., Ltd.

Statistical analysis. Data analysis was performed using SPSS software, version 10.0 (SPSS, Inc., Chicago, IL, USA). Analysis of variance or Wilcoxon statistical methods were used to determine statistical differences. All data are expressed as the mean \pm standard deviation. $\mathrm{P}<0.05$ was considered to indicate a statistically significant difference.

\section{Results}

Biochemical examination. At 4 weeks after surgery, ascites and jaundice were observed in the groups subjected to BDL, indicating that the BDL model was successfully established.

The serum levels of AST, ALT and TBIL in the cirrhosis group were significantly higher than those in the sham group $(\mathrm{P}<0.05)$. Furthermore, the levels were higher in the CoPP group and reduced in the $\mathrm{ZnPP}$ group compared with those in the cirrhosis group $(\mathrm{P}<0.05)$ (Table I). The serum levels of $\mathrm{H}_{2} \mathrm{~S}$ in the cirrhosis group were significantly lower than those in the sham group $(\mathrm{P}<0.05)$. Furthermore, serum $\mathrm{H}_{2} \mathrm{~S}$ was higher in the ZnPP group and lower in the CoPP group compared with that in the cirrhosis group $(\mathrm{P}<0.05)$. The levels of $\mathrm{COHb}$ in the arterial blood were significantly higher in the cirrhosis group than those in the sham group $(\mathrm{P}<0.05)$. Compared with the cirrhosis group, the $\mathrm{COHb}$ levels were significantly decreased in the $\mathrm{ZnPP}$ group $(\mathrm{P}<0.05)$ and significantly increased in the CoPP group $(\mathrm{P}<0.05)$. The PVP was significantly higher in the cirrhosis group than that in the sham group $(\mathrm{P}<0.05)$. Compared with the cirrhosis group, the PVP was significantly higher in the CoPP group and reduced in the ZnPP group $(\mathrm{P}<0.05)$ (Table II). 

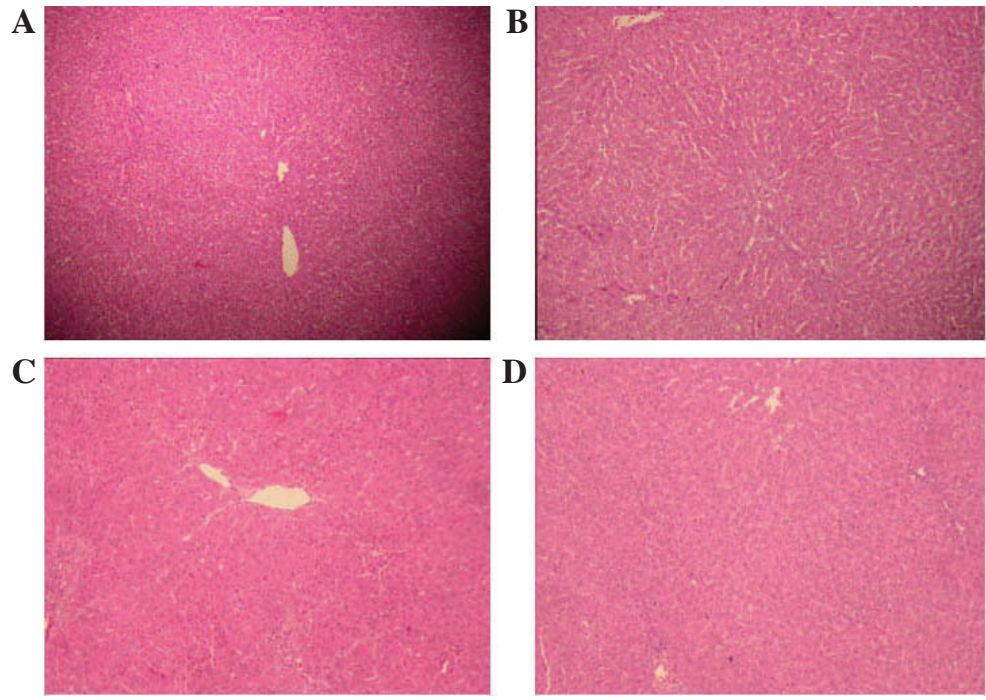

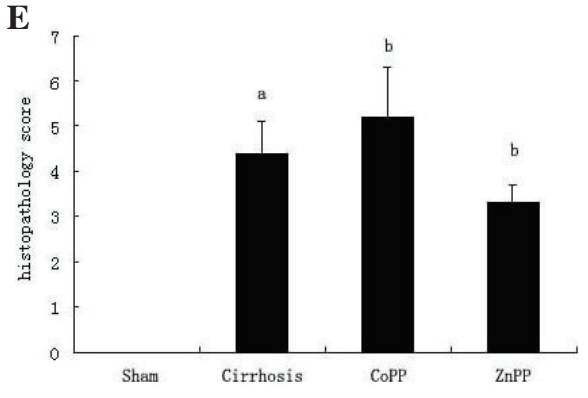

Figure 1. Representative photomicrographs showing pathological changes in the liver. (A) Normal structure of the liver; (B) liver cirrhosis; (C and D) liver structure in the (C) CoPP and (D) ZnPP groups (hematoxylin and eosin staining; magnification, x100). (E) Histopathological scores for fibrosis. Values are expressed as the mean \pm standard deviation. ${ }^{a} \mathrm{P}<0.01$ vs. sham group; ${ }^{b} \mathrm{P}<0.05$ vs. cirrhosis group. CoPP, cobalt protoporphyrin; ZnPP, zinc protoporphyrin IX.
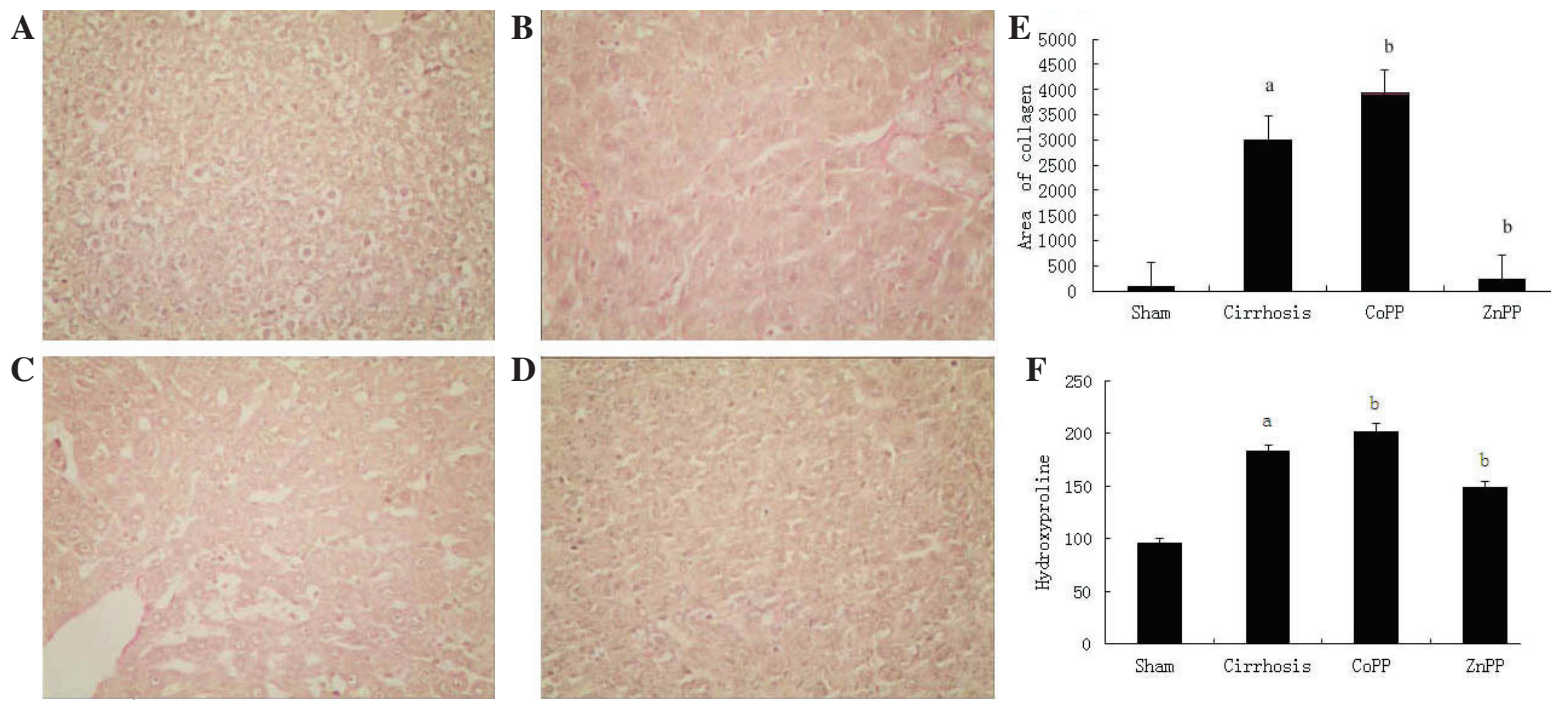

Figure 2. Van Gieson's staining of collagen type I in liver sections and liver hydroxyproline content. (A) Collagen type I was barely detectable in the sham group, showed marked deposition in the (B) cirrhosis and (C) CoPP groups, and was less prevalent in the (D) ZnPP group (magnification, x200). (E) Area of collagen type I. (F) Hydroxyproline content of liver tissue in different groups. Values are expressed as the mean \pm standard deviation. ${ }^{\text {a }}<0.01$ vs. sham group; ${ }^{\mathrm{b}} \mathrm{P}<0.05$ vs. cirrhosis group. CoPP, cobalt protoporphyrin; $\mathrm{ZnPP}$, zinc protoporphyrin IX.

Histopathological analysis of the liver. The degree of hepatic fibrosis was evaluated by H\&E staining. The sham group exhibited normal hepatic architecture, whereas the cirrhosis group exhibited the histological characteristics of bile duct proliferation and extensive fibrosis. Compared with the cirrhosis group, fibrous hyperplasia and fibrotic extensions with fibroblast proliferation were less prevalent in the ZnPP group and more prominent in the CoPP group (Fig. 1).

Collagen type I was observed using Van Gieson's staining (Fig. 2). In the cirrhosis group, collagen type I in the portal area and bile duct wall was markedly thicker than that in the sham group $(\mathrm{P}<0.01)$. Compared with the cirrhosis group, the extent of fibrosis was increased in the CoPP group and decreased in the ZnPP group. The change in HYP content in the liver tissue was in accordance with the change in type I collagen. Compared with the sham group, the HYP content was higher in the cirrhosis group. Compared with the cirrhosis group, the HYP content was higher in the CoPP group and lower in the $\mathrm{ZnPP}$ group $(\mathrm{P}<0.05)$.

Immunohistochemical detection of CSE and HO-1 protein expression levels. To localize the CSE and HO-1 protein expression levels in the livers, immunohistochemical analysis was conducted using specimens from the four groups. As shown in Fig. 3, the expression of the HO-1 protein was primarily located in Kupffer's cells and hepatocytes, which is consistent with the observations of previous studies $(17,18)$. In addition, the intensity and percentage of cells expressing HO-1 protein in the liver were detected. Mild staining was observed in hepatic tissue samples from the sham group, 

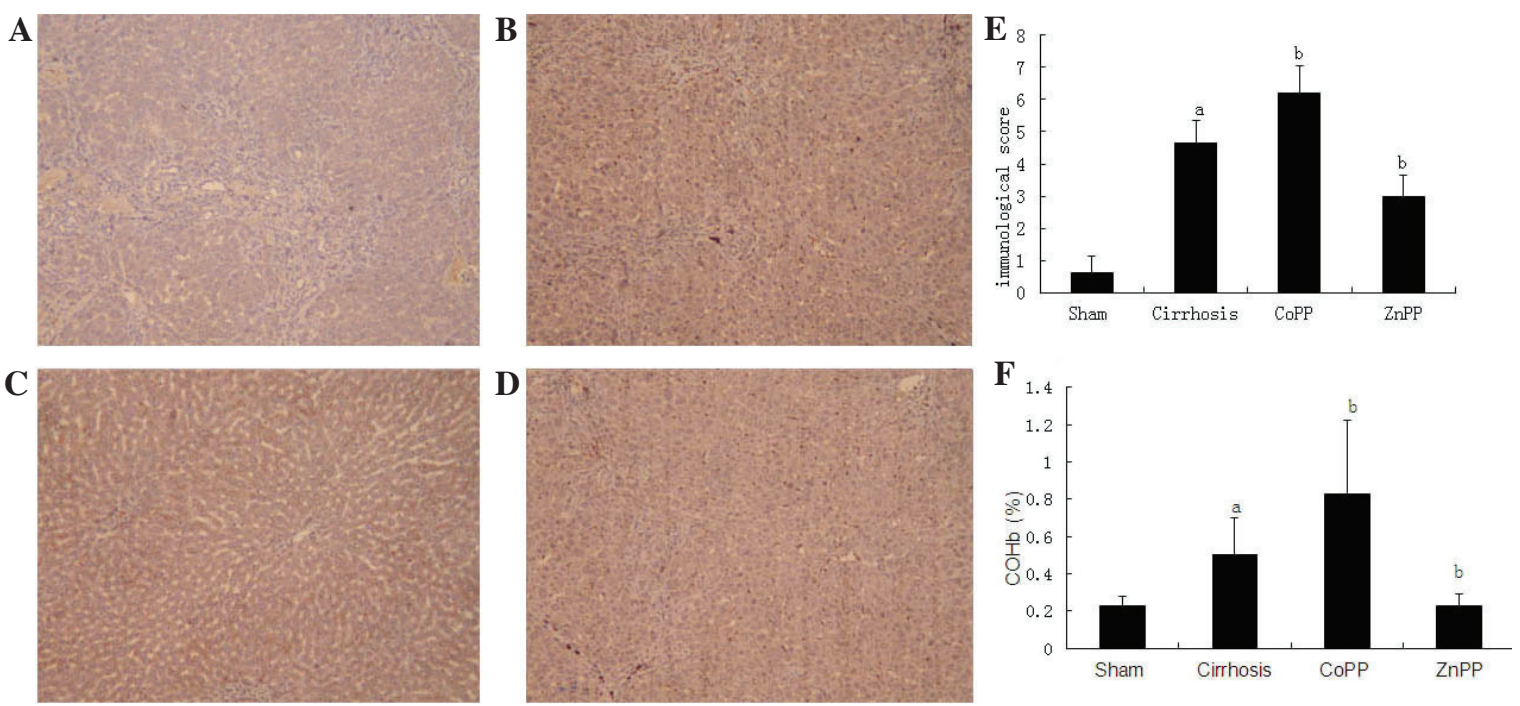

Figure 3. Hepatic HO-1 protein expression. Immunohistochemical staining of hepatic HO-1 protein in rats in the (A) sham, (B) cirrhosis, (C) CoPP and (D) ZnPP groups (magnification, x200). (E) Scores for the immunohistochemical staining of hepatic HO-1 protein expression in each group. (F) Levels of $\mathrm{COHb}$ were in accordance with $\mathrm{HO}-1$ expression. Values are expressed as the mean \pm standard deviation. ${ }^{\mathrm{a}} \mathrm{P}<0.01$ vs. sham group; ${ }^{\mathrm{b}} \mathrm{P}<0.05$ vs. cirrhosis group. HO-1, heme oxyenase-1; CoPP, cobalt protoporphyrin; ZnPP, zinc protoporphyrin IX; COHb, carboxyhemoglobin.
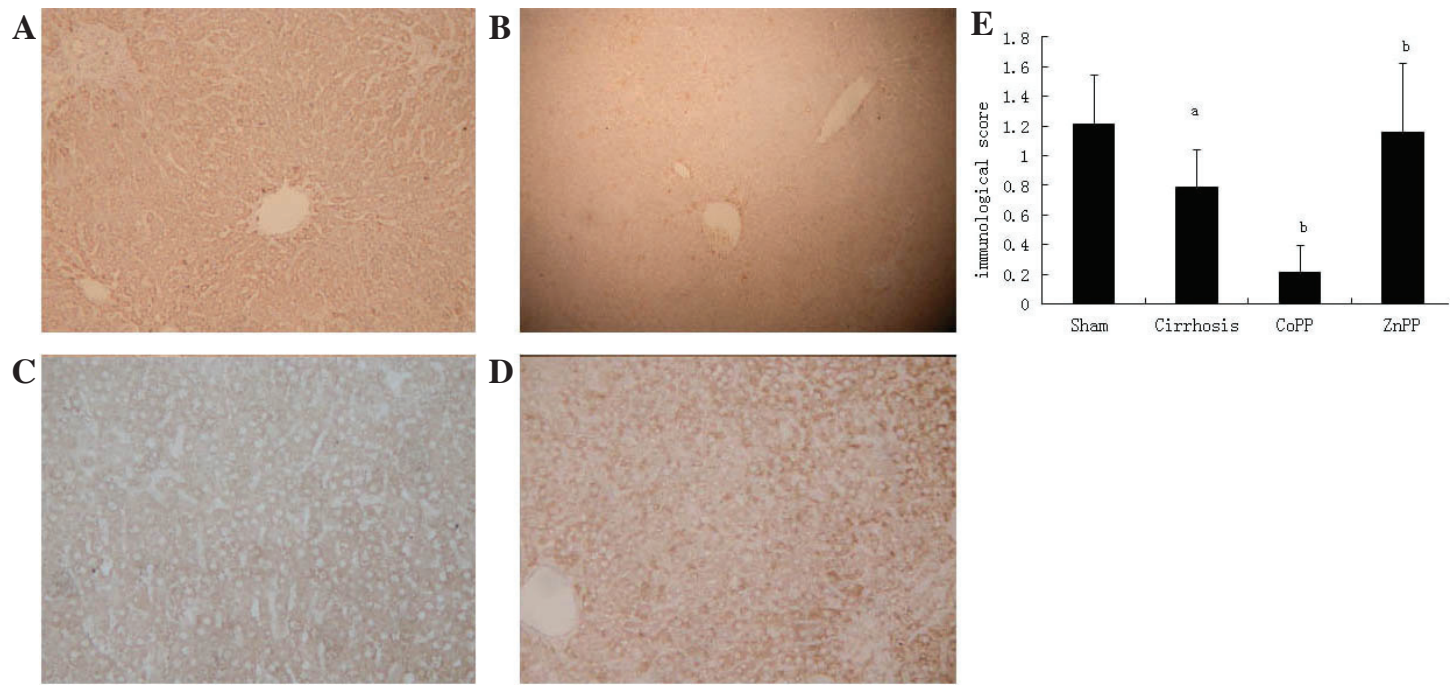

Figure 4. Hepatic CSE protein expression. Immunohistochemical staining of hepatic CSE protein in rats in the (A) sham, (B) cirrhosis, (C) CoPP and (D) ZnPP groups (magnification, $x 100$ ). (E) Scores for the immunohistochemical staining of hepatic CSE protein expression in each group. ${ }^{a} \mathrm{P}<0.01 \mathrm{vs.} \mathrm{sham} \mathrm{group;}$ ${ }^{b} \mathrm{P}<0.05$ vs. cirrhosis group. CSE, cystathionine- $\gamma$-lyase; CoPP, cobalt protoporphyrin; ZnPP, zinc protoporphyrin IX.

with a score of $0.63 \pm 0.51$. The HO-1 immunoreactivity was strongly positive in the cirrhosis group with a score of $4.63 \pm 0.72$, which was significantly higher than that in the sham group $(\mathrm{P}<0.01)$. Compared with the cirrhosis group, the HO-1 score was increased in the CoPP group (6.21 \pm 0.85$)$ and decreased in the ZnPP group $(2.98 \pm 0.68)$ (both $\mathrm{P}<0.05)$. The expression of the CSE protein was predominantly located in hepatocytes and hepatic stellate cells (HSCs) (Fig. 4), which is consistent with previous studies $(5,19)$. The intensity and percentage of cells expressing hepatic CSE protein were additionally evaluated. There was moderate positive staining in the sham group, with an overall score of $1.21 \pm 0.33$. The CSE score in the cirrhosis group was $0.79 \pm 0.25$, which was significantly reduced compared with that in the sham group $(\mathrm{P}<0.01)$. Compared with the cirrhosis group, the CSE score was further decreased in the CoPP group $(0.21 \pm 0.18)$,

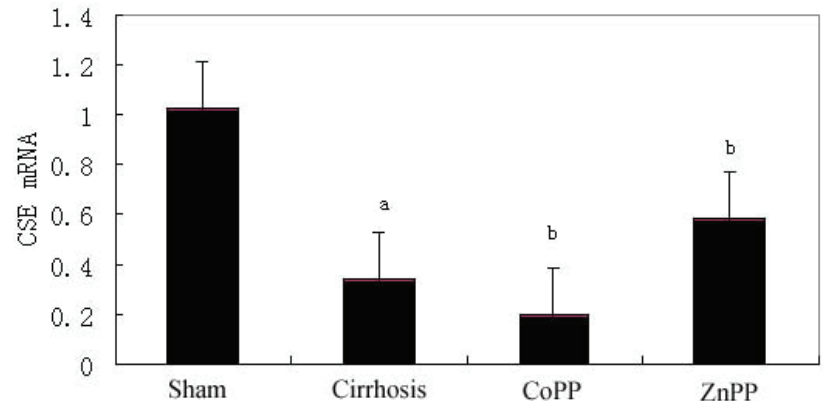

Figure 5. Hepatic CSE mRNA expression. Quantitative data showing the hepatic CSE mRNA expression levels. CSE mRNA levels were lower in the cirrhosis group than those in the sham group. Compared with the cirrhosis group, expression was significantly higher in the ZnPP group and lower in the CoPP group. ${ }^{\text {a }}<<0.01$ vs. sham group; ${ }^{\text {}} \mathrm{P}<0.05$ vs. cirrhosis group. $\mathrm{CSE}$, cystathionine- $\gamma$-lyase; CoPP, cobalt protoporphyrin; ZnPP, zinc protoporphyrin IX. 
whereas it was increased in the ZnPP group $(1.16 \pm 0.46)$ (both $\mathrm{P}<0.05$ ).

Hepatic CSE mRNA expression levels. As determined by qPCR, the hepatic expression levels of CSE mRNA in the cirrhosis group were significantly lower than those in the sham group $(\mathrm{P}<0.01)$. Furthermore, compared with the cirrhosis group, hepatic CSE mRNA expression levels were significantly decreased in the CoPP group, but significantly increased in the ZnPP group $(\mathrm{P}<0.05)$ (Fig. 5).

\section{Discussion}

Hyperdynamic circulation is a key characteristic of cirrhosis-induced portal hypertension, which is secondary to the presence of systemic vasodilation. Numerous hypotheses have been postulated regarding the development of systemic vasodilation, including increased synthesis of $\mathrm{NO}$ and $\mathrm{CO}$ and the activation of $\mathrm{K}_{\text {АтP }}$ channels in vascular smooth cells in the systemic and splanchnic arterial circulation $(4,20,21) \cdot \mathrm{H}_{2} \mathrm{~S}$ has been presented as a third endogenous signaling gasotransmitter, with similar properties to those of $\mathrm{NO}$ and $\mathrm{CO} . \mathrm{H}_{2} \mathrm{~S}$ is a crucial vasodilator in the hepatic microcirculation and causes relaxation of vascular smooth muscle (22). $\mathrm{H}_{2} \mathrm{~S}$ is produced endogenously from cysteine by pyridoxal-5'-phosphate-dependent enzymes, including cystathionine- $\beta$-synthase and CSE $(6,23)$, and induces vasorelaxation via the activation of ATP-sensitive $\mathrm{K}^{+}$channels in vascular smooth muscle (24). This mechanism of vasorelaxation induction differs from that of $\mathrm{NO}$ and $\mathrm{CO}(7,8)$. CSE is the primary enzyme in mammalian hepatic tissue for catalyzing the endogenous production of $\mathrm{H}_{2} \mathrm{~S}(13,19)$, and $>50 \%$ of the volume of gas in the liver appears to be derived from CSE $(13,19)$. To the best of our knowledge, the present study is the first to investigate whether the $\mathrm{H}_{2} \mathrm{~S} / \mathrm{CSE}$ pathway is involved in the formation of liver cirrhosis.

The results of the present study demonstrated that serum levels of ALT, AST and TBIL were significantly higher in the cirrhosis group than those in the sham group, indicating that BDL caused marked liver injury. The presence of liver cirrhosis was confirmed by H\&E staining in the livers of 4-week BDL rats. Additionally, the PVP was significantly higher in rats that underwent BDL compared with that in time-matched sham rats, indicating the presence of portal hypertension. These results suggested that the BDL model had been successfully established. The levels of $\mathrm{H}_{2} \mathrm{~S}$ were significantly lower in the cirrhosis group than those in the sham group. Furthermore, CSE protein and mRNA levels were significantly lower in the cirrhosis group than those in the sham group. A recent study by Wang et al (25) generated a similar result; it was observed that rats with portal hypertension had lower endogenous $\mathrm{H}_{2} \mathrm{~S}$ concentrations in comparison with healthy control rats and that the concentration was inversely associated with disease severity.

Previous studies have shown that $\mathrm{H}_{2} \mathrm{~S}$ is endogenously generated by vascular smooth muscle cells, while $\mathrm{CO}$ is primarily formed in vascular smooth muscle cells and partially in vascular endothelial cells. These observations suggest that $\mathrm{H}_{2} \mathrm{~S}$ and $\mathrm{CO}$ may interact in the regulation of biological functions (26-28); however, the interaction between the $\mathrm{CO} / \mathrm{HO}$ and $\mathrm{H}_{2} \mathrm{~S} / \mathrm{CSE}$ pathways remains unclear. A secondary aim of the present study was to investigate the effect of endogenous $\mathrm{CO}$ on the $\mathrm{H}_{2} \mathrm{~S} / \mathrm{CSE}$ pathway in the livers of cirrhotic rats by manipulating HO-1 enzyme activity via an intraperitoneal injection of either $\mathrm{ZnPP}$, a specific HO-1 enzyme inhibitor, or CoPP, a specific HO-1 enzyme inducer. The levels of $\mathrm{COHb}$ in the rat arterial blood were significantly higher in the cirrhosis group compared with those in the sham group, suggesting that overproduction of $\mathrm{CO}$ occurs in the rats with cirrhosis, as $\mathrm{CO}$ is predominately found bound to hemoglobin in the form of $\mathrm{COHb}$ in the circulation (29). Compared with the cirrhosis group, $\mathrm{COHb}$ levels were significantly lower in the ZnPP group and significantly higher in the CoPP group. HO-1 is the primary source of circulating $\mathrm{CO}$ (30), and the results of the present study showed that the levels of $\mathrm{COHb}$ were in accordance with HO-1 expression. Furthermore, the present results demonstrated that the serum levels of $\mathrm{H}_{2} \mathrm{~S}$ were significantly higher in the $\mathrm{ZnPP}$ group and significantly lower in the CoPP group, compared with the levels observed in the rats in the cirrhosis group. In addition, in comparison with the cirrhosis group, CSE protein and mRNA expression levels were significantly higher in the ZnPP group and significantly lower in the CoPP group. Collectively, these results suggest that endogenous $\mathrm{CO}$ is able to downregulate hepatic CSE expression in the livers of rats with cirrhosis.

The serum levels of AST, ALT and TBIL in the CoPP group were significantly higher than those in the cirrhosis group. Furthermore, compared with the cirrhosis group, more fibrous hyperplasia and fibrotic extensions with fibroblast proliferation were observed in the CoPP group. These differences indicated that the liver damage was more severe in the CoPP group than that in the cirrhosis group. In contrast to the levels of liver damage, the production of $\mathrm{H}_{2} \mathrm{~S}$ and hepatic CSE expression were reduced in the CoPP group compared with those in the cirrhosis group. The ZnPP group, however, exhibited decreased liver damage and increased $\mathrm{H}_{2} \mathrm{~S}$ production and hepatic CSE expression compared with the cirrhosis group. These results suggest that $\mathrm{H}_{2} \mathrm{~S}$ may serve a crucial function in protecting liver cells against the progression of liver fibrosis. Poliakova et al (31) observed that $\mathrm{H}_{2} \mathrm{~S}$ was able to induce biochemical restructuring of the rat liver, with long-term exposure ( $>2$ weeks) to a low dose and short-term exposure to a high dose of an $\mathrm{H}_{2} \mathrm{~S}$-containing gaseous mixture both leading to reversible changes in the liver. A potential mechanism by which $\mathrm{H}_{2} \mathrm{~S}$ inhibits liver fibrosis involves the induction of apoptosis (32) and inhibition of HSC activation $(22,33)$. In the present study, the increased severity of liver damage observed in the CoPP group may have been partially due to the lower production of $\mathrm{H}_{2} \mathrm{~S}$, as a result of inhibition by endogenous $\mathrm{CO}$.

Although previous reports have indicated that HO-1 performs a protective function in various liver diseases (34) and that the upregulation of $\mathrm{HO}-1$ prevents the progression of liver fibrosis in Mdr2-knockout mice (35), our previous study suggested that the overexpression of HO-1 is harmful to liver function and aggravates liver fibrosis in rats subjected to BDL (36). A potential reason underlying these conflicting results may be that HO-1 plays various roles in the progression of liver fibrosis (37), and the protection of HO-1 is restricted 
to a narrow threshold of expression (38). In the early stages of liver fibrosis, low HO-1 induction may be protective in liver cells (39); however, in the end stage of cirrhosis with portal hypertension, excessive HO-1 expression may deteriorate liver function and aggravate liver cirrhosis (36).

In conclusion, the present study indicates that vascular function cannot be independently regulated by a single molecule or its pathway (40). In addition to NO and CO, the $\mathrm{H}_{2} \mathrm{~S} / \mathrm{CSE}$ pathway is involved in the formation of liver cirrhosis, and $\mathrm{H}_{2} \mathrm{~S}$ may be involved in protecting liver cells against the progression of liver fibrosis. Endogenous $\mathrm{CO}$ downregulated the mRNA and protein expression levels of hepatic CSE, in addition to the production of $\mathrm{H}_{2} \mathrm{~S}$ in rats with liver cirrhosis. As $\mathrm{CO}$ and $\mathrm{H}_{2} \mathrm{~S}$ are produced in vascular smooth muscle cells, and have comparable characteristics and biological function to vasodilation, the dynamic interplay between $\mathrm{CO}$ and $\mathrm{H}_{2} \mathrm{~S}$ may have a significant role in the maintenance of homeostasis; however, the specific underlying mechanisms and interaction of these molecules with NO require further study.

\section{Acknowledgements}

This study was supported by grants from the National Natural and Science Foundation of China (no. 30970886) and the Initial Doctoral Foundation of Liaoning Province (no. 20121110).

\section{References}

1. Montaño-Loza A and Meza-Junco J: Pathogenesis of portal hypertension. Rev Invest Clin 57: 596-607, 2005 (In Spanish).

2. Guo SB, Li Q, Duan ZJ, Wang QM, Zhou Q and Sun XY: Octreotide attenuates liver fibrosis by inhibiting hepatic heme oxygenase-1 expression. Mol Med Rep 11: 83-90, 2015.

3. Li Volti G, Sacerdoti D, Di Giacomo C, Barcellona ML, Scacco A, Murabito P, Biondi A, Basile F, Gazzolo D, Abella R, et al: Natural heme oxygenase-1 inducers in hepatobiliary function. World J Gastroenterol 14: 6122-6132, 2008.

4. Tarquini R, Masini E, La Villa G, Barletta G, Novelli M, Mastroianni R, Romanelli RG, Vizzutti F, Santosuosso U and Laffi G: Increased plasma carbon monoxide in patients with viral cirrhosis and hyperdynamic circulation. Am J Gastroenterol 104 891-897, 2009.

5. Fiorucci S, Antonelli E, Mencarelli A, Orlandi S, Renga B, Rizzo G, Distrutti E, Shah V and Morelli A: The third gas: $\mathrm{H}_{2} \mathrm{~S}$ regulates perfusion pressure in both the isolated and perfused normal rat liver and in cirrhosis. Hepatology 42: 539-548, 2005.

6. Stipanuk MH and Beck PW: Characterization of the enzymic capacity for cysteine desulphhydration in liver and kidney of the rat. Biochem J 206: 267-277, 1982.

7. Geng B, Yang J, Qi Y, Zhao J, Pang Y, Du J and Tang C: $\mathrm{H}_{2} \mathrm{~S}$ generated by heart in rat and its effects on cardiac function. Biochem Biophys Res Commun 313: 362-368, 2004.

8. Zhao W, Zhang J, Lu Y and Wang R: The vasorelaxant effect of $\mathrm{H}(2) \mathrm{S}$ as a novel endogenous gaseous K(ATP) channel opener. EMBO J 20: 6008-6016, 2001.

9. Hartsfield CL: Cross talk between carbon monoxide and nitric oxide. Antioxid Redox Signal 4: 301-307, 2002.

10. Altaany Z, Yang G and Wang R: Crosstalk between hydrogen sulfide and nitric oxide in endothelial cells. J Cell Mol Med 17: 879-888, 2013.

11. Li RN, Zeng XJ, Chen YH, Lu LQ and Hao G: Interaction between hydrogen sulfide and nitric oxide on cardiac protection in rats with metabolic syndrome. Zhong Guo Yi Xue Ke Xue Yuan Xue Bao 33: 25-32, 2011 (In Chinese).

12. Jin HF, Du JB, Li XH, Wang YF, Liang YF and Tang CS: Interaction between hydrogen sulfide/cystathionine gamma-lyase and carbon monoxide/heme oxygenase pathways in aortic smooth muscle cells. Acta Pharmacol Sin 27: 1561-1566, 2006.

13. Kabil O, Vitvitsky V, Xie P and Banerjee R: The quantitative significance of the transsulfuration enzymes for $\mathrm{H}_{2} \mathrm{~S}$ production in murine tissues. Antioxid Redox Signal 15: 363-372, 2011.
14. Pereira RM, dos Santos RA, Oliveira EA, Leite VH, Dias FL, Rezende AS, Costa LP, Barcelos LS, Teixeira MM and Simoes e Silva AC: Development of hepatorenal syndrome in bile duct ligated rats. World J Gastroenterol 14: 4505-4511, 2008.

15. Amersi F, Buelow R, Kato H, Ke B, Coito AJ, Shen XD, Zhao D, Zaky J, Melinek J, Lassman CR, et al: Upregulation of heme oxygenase-1 protects genetically fat Zucker rat livers from ischemia/reperfusion injury. J Clin Invest 104: 1631-1639, 1999.

16. Brown KE, Poulos JE, Li L, Soweid AM, Ramm GA, O'Neill R, Britton RS and Bacon BR: Effect of vitamin E supplementation on hepatic fibrogenesis in chronic dietary iron overload. Am J Physiol 272: G116-G123, 1997.

17. Makino N, Suematsu M, Sugiura Y, Morikawa H, Shiomi S, Goda N, Sano T, Nimura Y, Sugimachi K and Ishimura Y: Altered expression of heme oxygenase-1 in the livers of patients with portal hypertensive diseases. Hepatology 33: 32-42, 2001.

18. Wei CL, Lee KH, Khoo HE and Hon WM: Expression of haem oxygenase in cirrhotic rat liver. J Pathol 199: 324-334, 2003.

19. Fujii K, Sakuragawa T, Kashiba M, Sugiura Y, Kondo M, Maruyama K, Goda N, Nimura Y and Suematsu M: Hydrogen sulfide as an endogenous modulator of biliary bicarbonate excretion in the rat liver. Antioxid Redox Signal 7: 788-794, 2005.

20. Leung TM, Fung ML, Liong EC, Lau TY, Nanji AA and Tipoe GL: Role of nitric oxide in the regulation of fibrogenic factors in experimental liver fibrosis in mice. Histol Histopathol 26: 201-211, 2011.

21. Matei V, Rodríguez-Vilarrupla A, Deulofeu R, García-Calderó H, Fernández M, Bosch J and Garcia-Pagán JC: Three-day tetrahydrobiopterin therapy increases in vivo hepatic NOS activity and reduces portal pressure in $\mathrm{CCl} 4$ cirrhotic rats. J Hepatol 49: 192-197, 2008.

22. Liu Y, Li Y, Yang W and Cao G: $\mathrm{H}_{2} \mathrm{~S}$ inhibits the activation of hepatic stellate cells and downregulates the expression of urotensin II. Hepatol Res 43: 670-678, 2013.

23. Kamoun P: Endogenous production of hydrogen sulfide in mammals. Amino Acids 26: 243-254, 2004.

24. Cheng Y, Ndisang JF, Tang G, Cao K and Wang R: Hydrogen sulfide-induced relaxation of resistance mesenteric artery beds of rats. Am J Physiol Heart Circ Physiol 287: H2316-H2323, 2004.

25. Wang C, Han J, Xiao L, Jin CE, Li DJ and Yang Z: Role of hydrogen sulfide in portal hypertension and esophagogastric junction vascular disease. World J Gastroenterol 20: 1079-1087, 2014.

26. Ebrahimkhani MR, Mani AR and Moore K: Hydrogen sulphide and the hyperdynamic circulation in cirrhosis: A hypothesis. Gut 54: 1668-1671, 2005.

27. Zhang CY, Li XH, Zhang T, Fu J and Cui XD: Hydrogen sulfide upregulates heme oxygenase-1 expression in rats with volume overload-induced heart failure. Biomed Rep 1: 454-458, 2013.

28. Zhang QY, Du JB, Zhou WJ, Yan H, Tang CS and Zhang CY: Impact of hydrogen sulfide on carbon monoxide/heme oxygenase pathway in the pathogenesis of hypoxic pulmonary hypertension. Biochem Biophys Res Commun 317: 30-37, 2004.

29. Guo SB, Duan ZJ, Li Q and Sun XY: Effect of heme oxygenase-1 on renal function in rats with liver cirrhosis. World J Gastroenterol 17: 322-328, 2011.

30. Naik JS, O'Donaughy TL and Walker BR: Endogenous carbon monoxide is an endothelial-derived vasodilator factor in the mesenteric circulation. Am J Physiol Heart Circ Physiol 284: H838-H845, 2003.

31. Poliakova VS, Shakhlamov VA, Stadnikov AA and Solnyshkova TG: Structural-biochemical reorganization of rat liver caused by hydrogen sulfide-containing gas mixture. Morfologiia 124: 84-87, 2003 (In Russian).

32. Fan HN, Wang HJ, Yang-Dan CR, Wang C, Li YF and Deng Y: Protective effects of hydrogen sulfide on oxidative stress and fibrosis in hepatic stellate cells. Mol Med Rep 7: 247-253, 2013.

33. Lu F, Xing J, Zhang X, Dong S, Zhao Y, Wang L, Li H, Yang F, $\mathrm{Xu} \mathrm{C}$ and Zhang W: Exogenous hydrogen sulfide prevents cardiomyocyte apoptosis from cardiac hypertrophy induced by isoproterenol. Mol Cell Biochem 381: 41-50, 2013.

34. Yang H, Zhao LF, Zhao ZF, Wang Y, Zhao JJ and Zhang L: Heme oxygenase-1 prevents liver fibrosis in rats by regulating the expression of PPAR $\gamma$ and NF- $\kappa$ B. World J Gastroenterol 18: 1680-1688, 2012

35. Barikbin R, Neureiter D, Wirth J, Erhardt A, Schwinge D, Kluwe J, Schramm C, Tiegs G and Sass G: Induction of heme oxygenase 1 prevents progression of liver fibrosis in Mdr2 knockout mice. Hepatology 55: 553-562, 2012. 
36. Wang QM, Du JL, Duan ZJ, Guo SB, Sun XY and Liu Z: Inhibiting heme oxygenase-1 attenuates rat liver fibrosis by removing iron accumulation. World J Gastroenterol 19: 2921-2934, 2013.

37. Wang QM, Duan ZJ, Du JL, Guo SB, Sun XY and Liu Z: Heme oxygenase/carbon monoxide pathway inhibition plays a role in ameliorating fibrosis following splenectomy. Int J Mol Med 31: $1186-1194,2013$.

38. Geuken E, Buis CI, Visser DS, Blokzijl H, Moshage H, Nemes B, Leuvenink HG, de Jong KP, Peeters PM, Slooff MJ and Porte RJ: Expression of heme oxygenase-1 in human livers before transplantation correlates with graft injury and function after transplantation. Am J Transplant 5: 1875-1885, 2005.
39. Duan ZJ, Yang D, Wang F, Sun YJ, Sun XY and Zheng ML: Heme oxygenase-1 regulates the major route involved in formation of immune hepatic fibrosis in rats. Chin Med J (Engl) 123: 3304-3308, 2010

40. Weston AD and Hood L: Systems biology, proteomics and the future of health care: Toward predictive, preventative, and personalized medicine. J Proteome Res 3: 179-196, 2004. 